Department of Theriogenology

Faculty of Veterinary Medicine, Assiut University

\title{
SEROLOGICAL AND PATHOLOGICAL STUDIES ON ENDEMIC BRUCELLOSIS IN SHEEP AND GOAT IN ASSIUT AND SOHAG PROVINCES
}

(With 2 Tables and 10 Figures)

\author{
By \\ A.KH. ABDEL-RAZEK; S.KH. ABD-ELGHAFFAR* \\ and I.A. FOUAD** \\ * Dept. of Pathology, Fac. Vet. Med., Assiut Univ. \\ ** Animal Health research Institute, Assiut Lab.
}

(Received at 21/3/2006)

\section{دراسات مصلية ومرضية علي مرض الأبروسيلا في الأغنام والماعز بمحافظتي أسبيوط وسوهي مزئ}

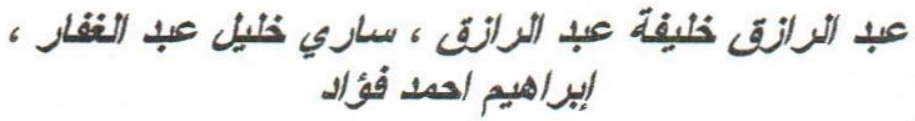

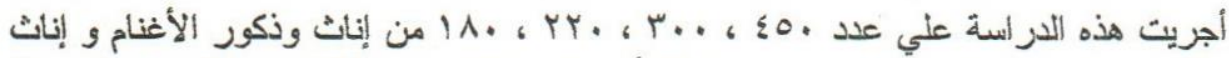

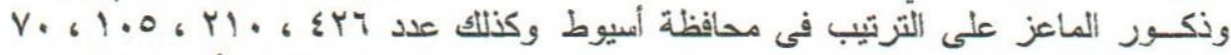

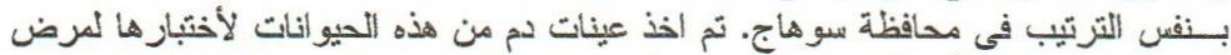

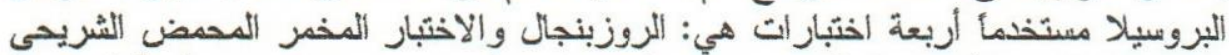

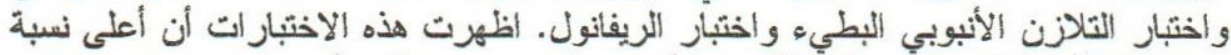

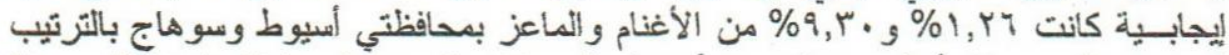

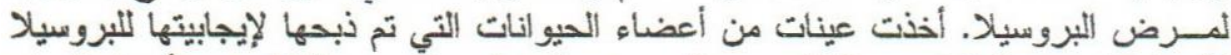

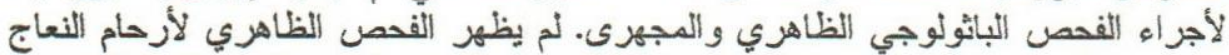

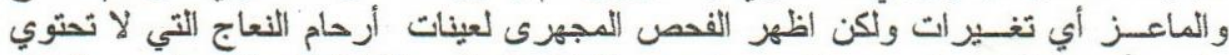

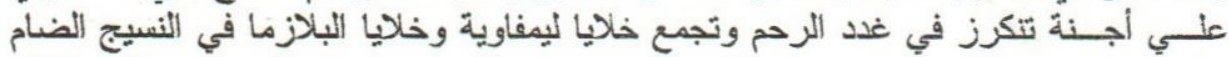

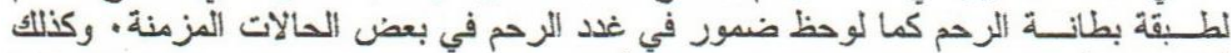

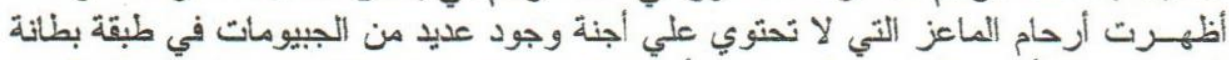

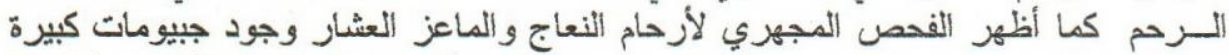

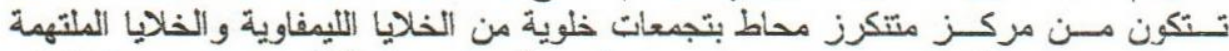

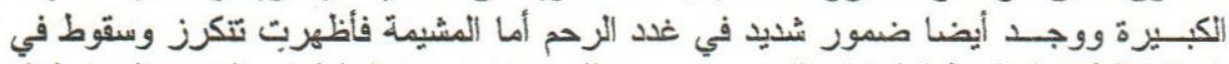

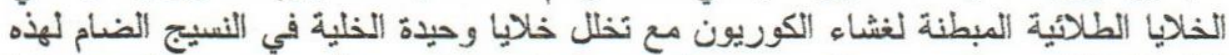

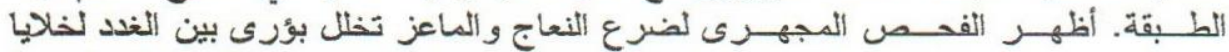
الالـــهاب مع تنكرز للخلايا الغدية. العقد الليمفاوية وخاصة اللفوق ضرعية والجار بلعومية 


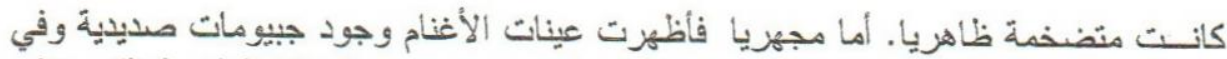

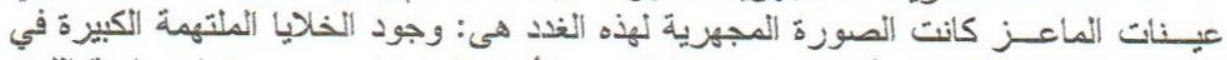

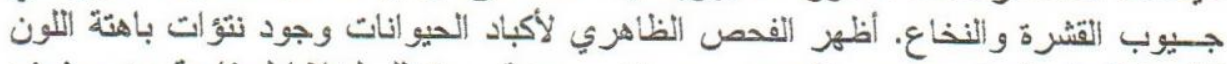

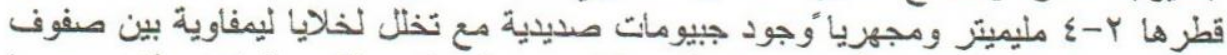

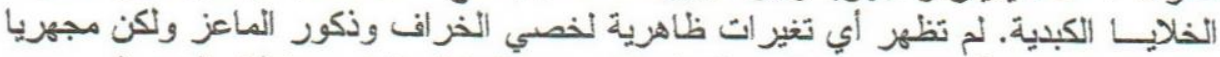

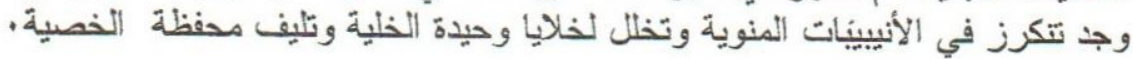

\section{SUMMARY}

A total number of $450,300,220$ and 180 blood samples from ewes, rams, does and bucks respectively were collected in Assiut province and another 426, 210, 105 and 70 samples from the same species respectively were collected in Sohag province. The collected blood samples were screened for detection of brucella antibodies using Rose Bengal plate antigen test (RBPT), buffered acidified plate antigen tests (BAPAT), tube agglutination test (TAT) and Rivanol Tube test (RTT). $1.26 \%$ and $9.30 \%$ of animals were found to be the positive percentage in Assiut and Sohag provinces respectively. B.A.P.T. showed the highest number of positive reactor animals. No gross lesions could be detected in pregnant and non-pregnant uteri of ewes and goats. Microscopically, the non-gravid uterus of ewes revealed necrobiotic changes of the endometrial glands and diffuse aggregations of plasma cells and lymphocytes in the lamina propria. In chronic cases, atrophy of the endometrial glands was observed. The uterus of non-pregnant goat revealed presence of multiple endometrial granulomas composed of a necrotic center surrounded by proliferated fibrous connective tissue and mononuclear cells. In pregnant ewes and goats, the uterus revealed presence of large granulomas and the glandular epithelium of the endometrial glands was extensively atrophied. The placenta in these cases showed necrosis and desquamation of the chorionic epithelium and the lamina propria revealed few to moderate mononuclear cell infiltrations and fibrous connective tissue proliferations. The udder of sero-positive ewes and goats showed focal and inter-acinar inflammatory cell infiltrations, which is mostly composed of lymphocytes and plasma cells with necrobiotic changes in the acinar epithelium. The supramammary and retropharyngeal lymph nodes of sero-positive cases in sheep and goats were enlarged. Microscopically in ewes showed presence of pyogranuloma, while in goats the lymph nodes showed moderate changes represented by sinus macrophagal reactions in both cortex and medulla. The liver revealed presence of pyogranulomas 
composed of aggregated neutrophils surrounded by a layer of proliferated connective tissue and lymphocytic infiltration in-between hepatic cords. No changes could be detected grossly in testes of rams and bucks and the microscopic lesions were nearly similar in sheep and goats. The testes showed fibrous periorchitis and the parenchyma revealed necrosis of seminiphrous tubules and mononuclear cell infiltrations. Finally, it was concluded that, diagnosis of brucellainfected animals is based on the evaluations of history as well as screening of serum samples and correlating gross and microscopic lesions.

Key words: Brucellosis, sheep and goats, serology, histopatholgy

\section{INTRODUCTION}

Brucellosis is an infectious disease of worldwide importance in domestic animals and the causative bacteria are transmitted to humans through contact with infected livestock or by consumption of contaminated dairy product. It also proved to cause heavy economic damage in livestock production. Surveillance for Brucellosis in animals is of great importance and considered the corner stone for better understanding of the epidemiology of the disease and improving the control and eradication polices. Brucellosis remains a major zoonotic disease worldwide. Although many countries have eradicated Brucella abortus from cattle, in some areas $B$. melitensis has emerged as a cause of infection in this species as well as in sheep and goats. B. melitensis primarily affects the reproductive tract of sheep and goats, and $B$. melitensis infection is characterized by abortion, retained placenta and, to a lesser extent, impaired fertility. Although $B$. melitensis infects mainly sheep and goats it is a zoonosis that plays a significant role in the national economy and the public health of many developing countries (FAO, WHO, OIE, 1993).

Animals may contract brucellosis by oral or cutaneous routes, or at birth. Infection by inhalation is also possible when healthy and aborting animals are kept in overcrowded pens with poor sanitary measures. Transmission of $B$. melitensis from flock to flock usually follows the movement of infected pregnant females. However, it can also occur via an infected male. Wild animals and dogs may transmit parts of aborted fetuses to other areas (Alton, 1985; Mikolon et al., 1998). 
The disease is enzootic among Egyptian sheep and goats as $B$. melitensis had been isolated (Hamdy, 1992). Increasing the importation of animals and establishment of large farms in the last thirty years was accompanied with high rate of brucella reactors. This has been documented by Barsoum (1980), Shalaby (1986), Selim (1987), Hamdy (1989). In the same issue, Refai (1994) cited that, the data published by the General Organization for Veterinary Services (GOVS) in its annual veterinary technical reports showed that, the incidence of brucellosis in sheep and goat was highest in the years $1982(8.7 \%)$ and $1985(9.4 \%)$. It started to drop sharply in the year $1986(1.2 \%)$ and $1992(0.67 \%)$.

Although not formally validated for use in sheep and goats, the Rose Bengal plate agglutination test, the complement fixation test, and more recently the ELISA have been used for the serological diagnosis of brucellosis in sheep and goats (Garin-Bastuji et al. 1998). A combination of tests shows a degree of sensitivity and specificity, which appears sufficient to detect infected animals, and removal of those animals appears to contribute to disease control when vaccination is avoided. Garin-Bastuji et al., (1998) also, reported that, while several ELISA tests have been developed recently, the Rose Bengal plate agglutination and complement fixation tests, based on the detection of anti-S-LPS antibody, are still recommended for screening flocks and individuals. However, these tests sometimes lack specificity or sensitivity.

In some countries, the test and slaughter policy together with the vaccination of young females is adopted, in others, particularly with regard to sheep and goats; mass vaccination has been recently started. The most commonly used vaccines are B. abortus $\mathrm{S} 19$ and $B$. melitensis Rev. 1 vaccines. $B$. abortus RB51 vaccine is used in some countries on small scale. Vaccination is limited to cattle and small ruminants (Refai, 2002).

Brucellosis needs a collective approach using all available data in order to achieve proper diagnosis. This work is planed to study diagnosis of brucellosis using four serological tests as well as histopathological changes accompanying the natural infection of sheep and goat in Assiut and Sohag provinces.

\section{MATERIALS and METHODS}

The present study was conducted during the year 2004-2005. Animals used in this work belonged to several villages existing in Assiut and Sohag provinces. The complains of stock holders were: abortion of 
pregnant animals, retention of placenta, decreased fertility, metritis in females and orchitis in males.

A total number of $450,300,220$ and 180 blood samples from ewes, rams, does and bucks respectively were collected at random in Assiut province and another 426, 210, 105 and 70 samples for the same species respectively were collected in Sohag province. Collection of blood was done by jugular veinpuncture. The collected blood samples were kept in refrigerator over night and centrifuged foer $20 \mathrm{~min}$. at 3000 $\mathrm{rpm}$. The serum is aspirated and transferred to $3 \mathrm{ml}$ clean dry Ependorf tubes where it kept in deep freezer till the time of examination.

All the samples were screened for detection of brucella antibodies using Rose Bengal plate antigen test (RBPT), buffered acidified plate antigen tests (BAPAT), tube agglutination test (TAT) and Rivanol Tube test (RTT)

Pathological examination was carried out on serologically positive cases which were slaughtered and specimens of uterus, lymph nodes, udders, liver, placenta of gravid uterus as well as testes were taken. The samples were fixed in 10\% neutral buffered formalin. Fixed tissues were dehydrated in ascending series of alcohols and processed for paraffin embedding technique. Sections were stained with haematoxyline and eosin (HE, Bancroft \& Stevens, 1982)

\section{RESULTS}

Table (1) illustrates the results of examined animals by different serological tests and the distribution of positive animals between the two species in both sexes. Out of 1150 sheep and goat examined in Assiut province, mean of positive animal through the four serological tests was 14.5 , which represents only $1.26 \%$ of tested animals. The B.A.P.A.T. showed the highest positive number. Ewes were more infected than rams. In Sohag province mean of positive animals detected through the four serological tests was 75.7. and the B.A.P.A.T. also showed the highest number of positive animals. Table 2 illustrates the distribution of the results among the two species where the sheep were more infected than goats and ewes showed more positive cases than rams.

No gross lesions could be detected in pregnant and non-pregnant uteri of positive reactor ewes and goats. Microscopically, the non-gravid uterus of ewes revealed necrobiotic changes of the endometrial gland and diffuse aggregations of plasma cells and lymphocytes in the lamina propria (Fig. 1). In chronic cases, atrophy of the endometrial glands was 
observed (Fig. 2). The uterus of non-pregnant goat revealed presence of multiple endometrial granulomas composed of a necrotic center surrounded by proliferated fibrous connective tissue and mononuclear cells (Fig. 3).

In pregnant ewes and goats, the histopathological picture of the uterus revealed presence of large granuloma composed of necrotic center and aggregations of lymphocytes and macrophages. The glandular epithelium of the endometrial glands was extensively atrophied (Fig. 4). The placenta in these cases showed necrosis and desquamation of the chorionic epithelium and the lamina propria revealed few to moderate mononuclear cell infiltrations mostly lymphocytes and fibrous connective tissue proliferations (Fig. 5)

The gross picture of the udder of sero-positive ewes and goats showed no changes except in two ewes where the udder felt rigid in texture. Mieroscopically, the lesions in both species presented focal and inter-acinar inflammatory cell infiltrations, which are mostly composed of lymphocytes and plasma cells. The acinar epithelium showed necrobiotic changes (Fig. 6)

The supramammary and retropharyngeal lymph nodes of seropositive cases in sheep and goats appeared enlarged grossly. The microscopic picture of ewes showed presence of pyogranuloma surrounded by fibrous connective tissue proliferations and inflammatory cell infiltrations composed mainly of lymphocytes and macrophages (Fig. 7).While in goats. The lymph nodes showed somewhat moderate changes represented by sinus macrophagal reactions in both cortex and medulla (Fig. 8)

Grossly, the liver in some cases showed presence of pale colored nodules with 2-4 mm diameter. Microscopically, the liver lesions in sheep and goats revealed presence of pyogranuloma composed of aggregated neutrophils surrounded by a layer of proliferated connective tissue and lymphocytic infiltration inbetween hepatic cords (Fig. 9).

No changes could be detected grossly in testes of rams and bucks and the microscopic lesions were nearly similar in sheep and goats. The testes showed fibrous periorchitis and the parenchyma revealed necrosis of seminiferous tubules and mononuclear cell infiltrations (Fig. 10). 
Assiut Vet. Med. J. Vol. 52 No. 109 April 2006

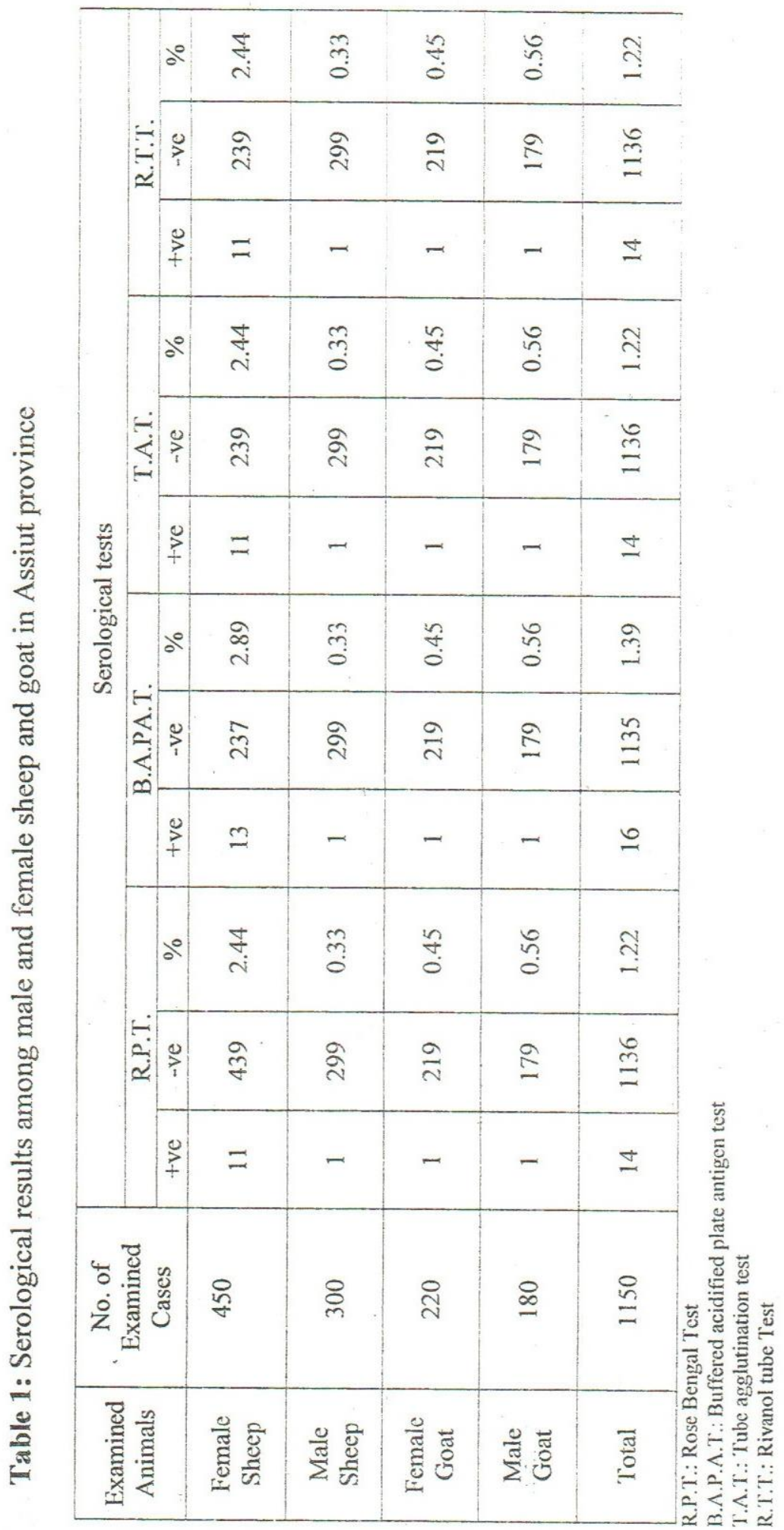


Assiut Vet. Med. J. Vol. 52 No. 109 April 2006

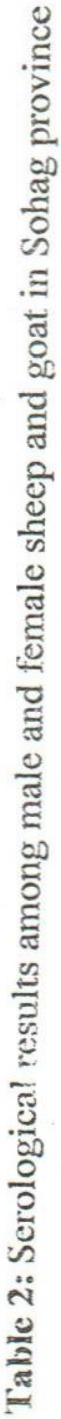

\begin{tabular}{|c|c|c|c|c|c|}
\hline$\partial^{\circ}$ & ્ֻণ & $\stackrel{\vec{q}}{\sim}$ & $\stackrel{9}{-}$ & $\begin{array}{l}0 \\
\infty \\
\end{array}$ & $\hat{\sigma}$ \\
\hline & & & & & \\
\hline
\end{tabular}

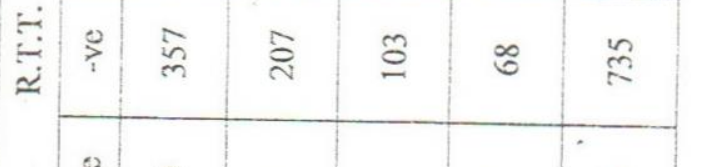

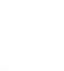

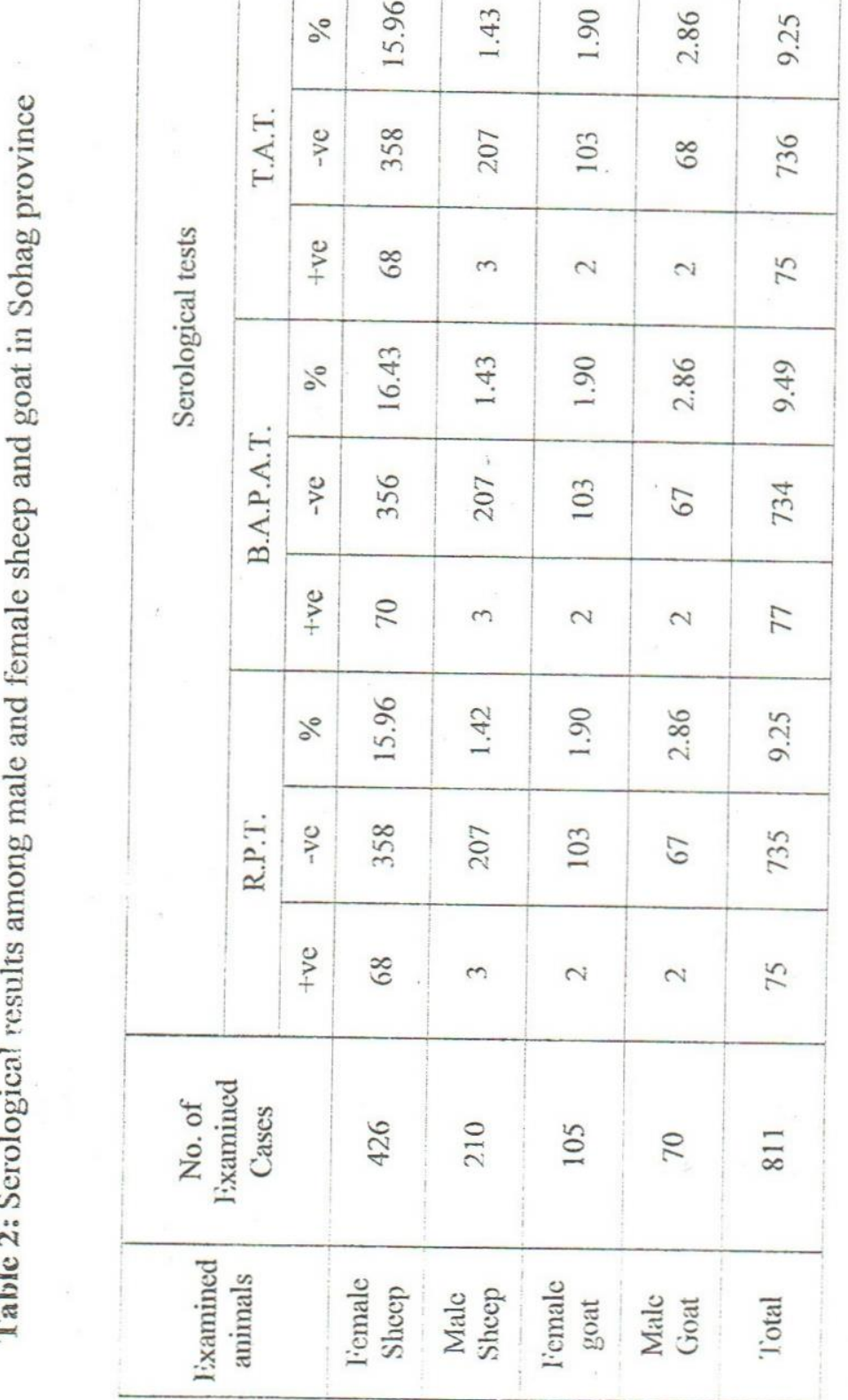

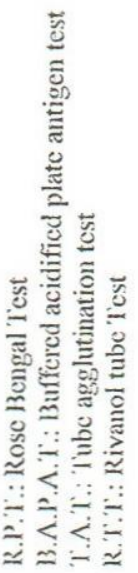


Fion a a. 2: $\%$

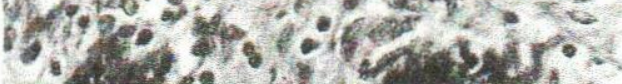

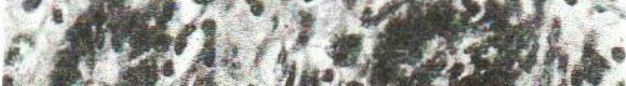

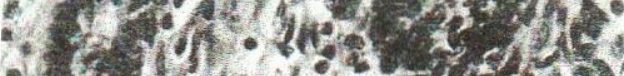
Hor trots

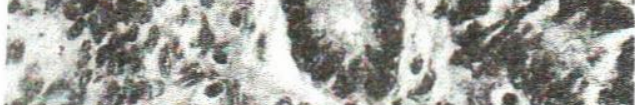
7 .

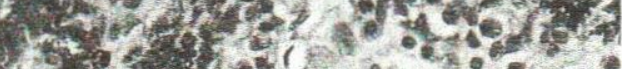

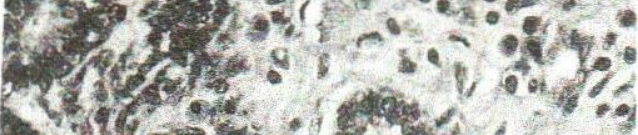

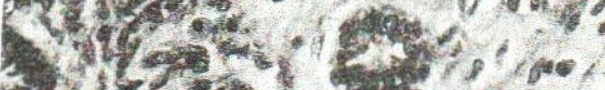

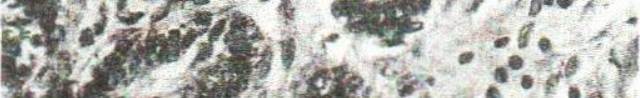

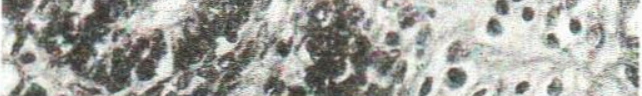

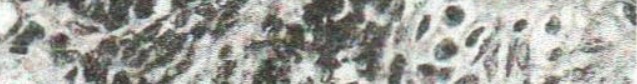

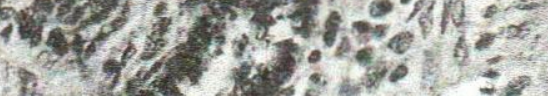

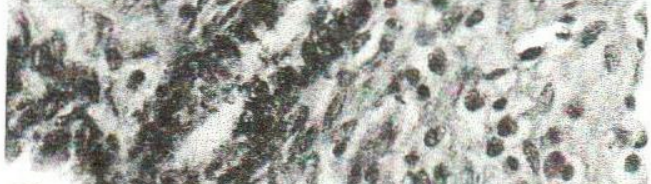
1 . 242
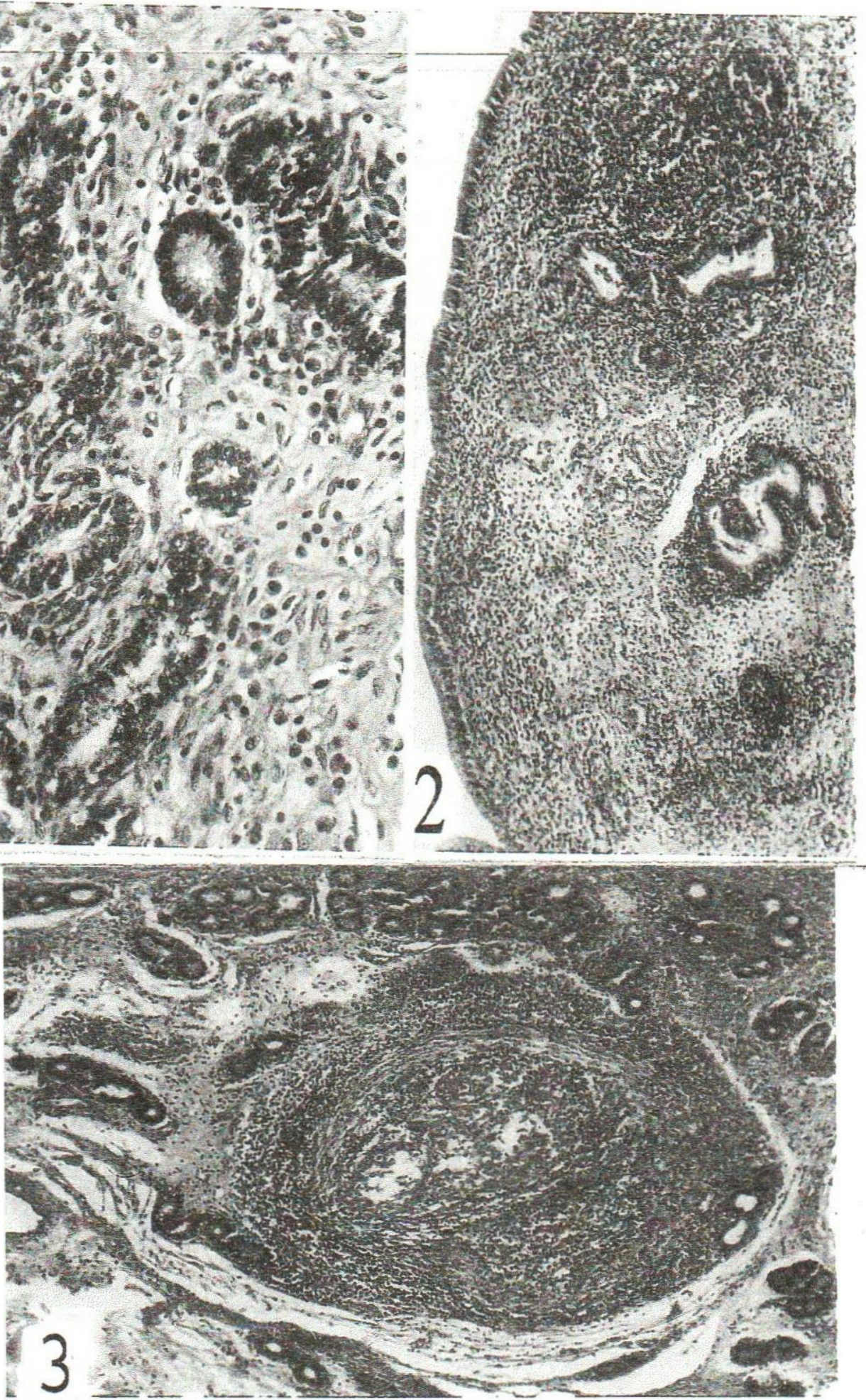


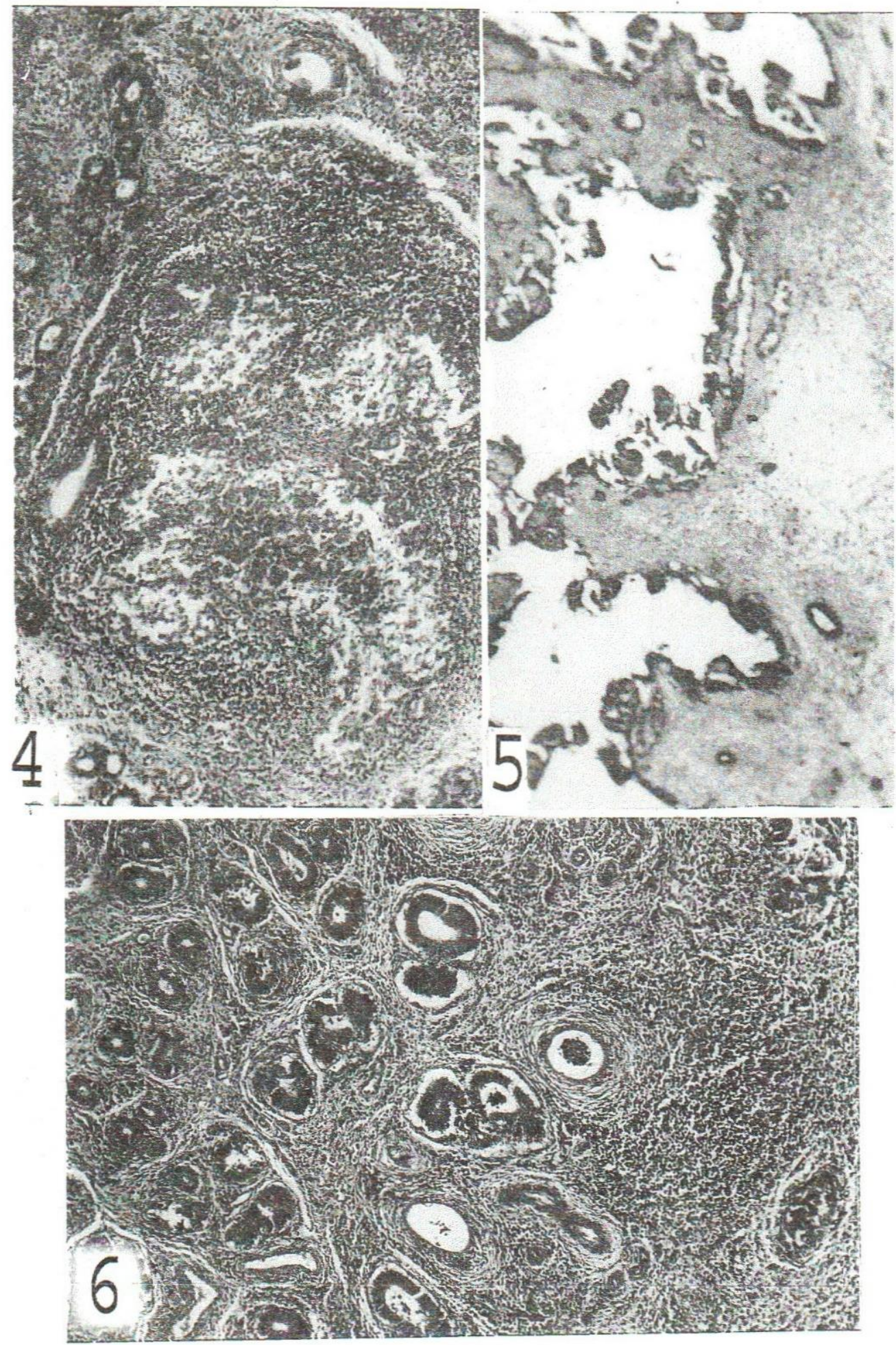




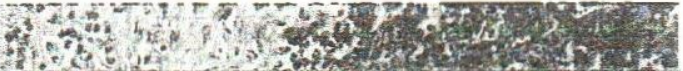
-

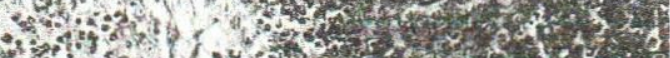

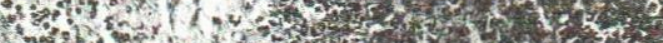
ng.

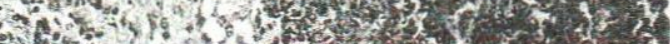

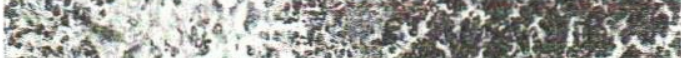

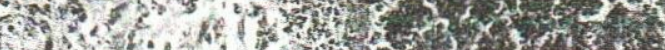

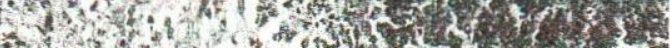
of 5 .

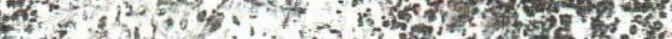

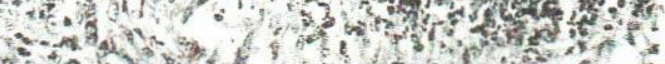

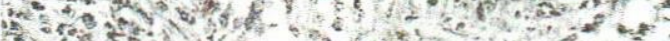
3.

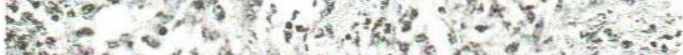

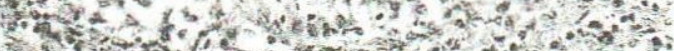

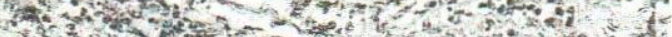

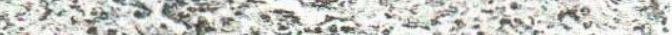

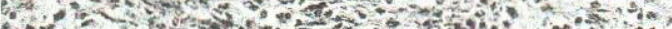
cis 210 of

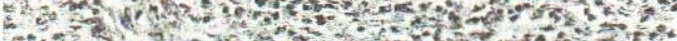

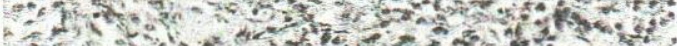

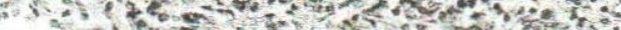

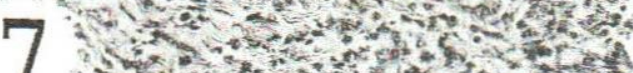

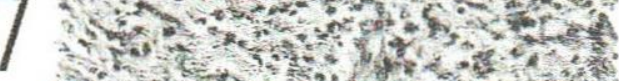
10

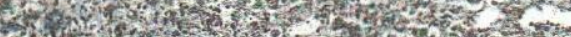
7.

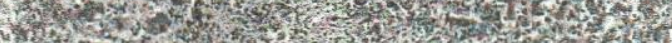

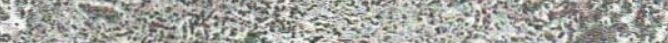

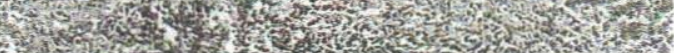

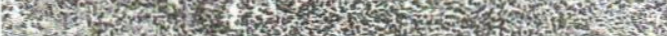

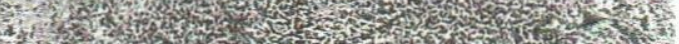

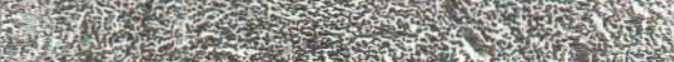

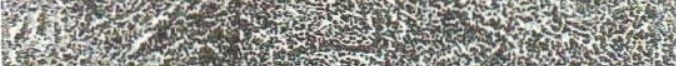

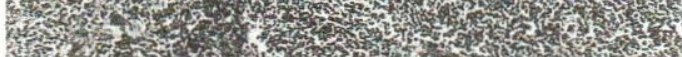

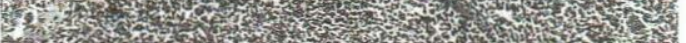

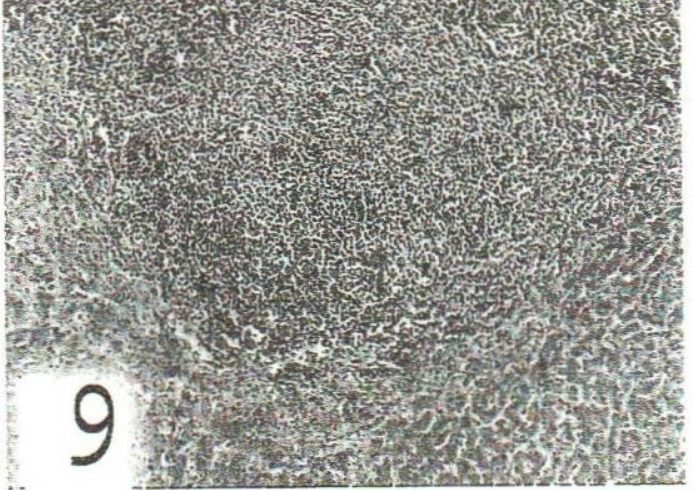

\& 1. * 70 D.

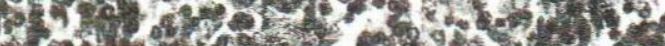

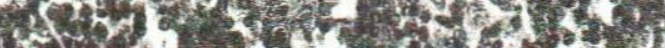

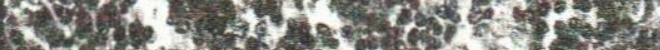

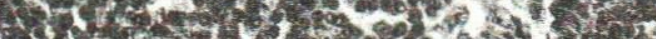

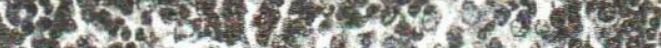

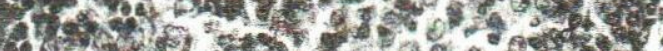

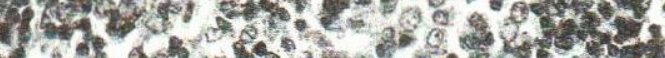

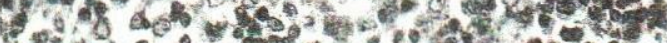
i. b.5.

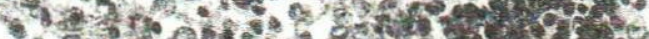

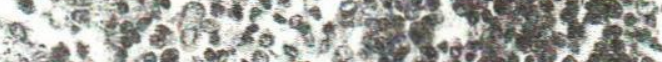

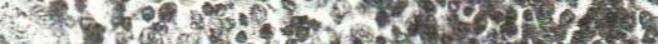

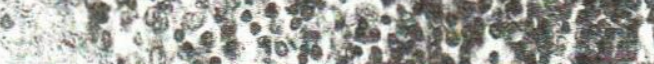

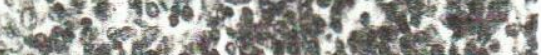
3.

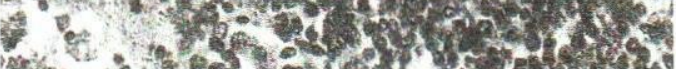

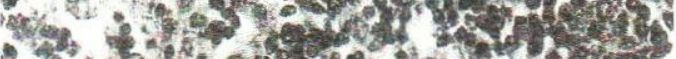

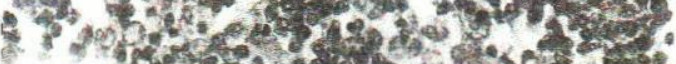

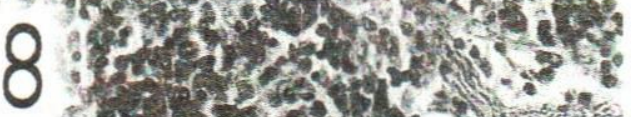

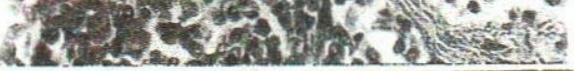

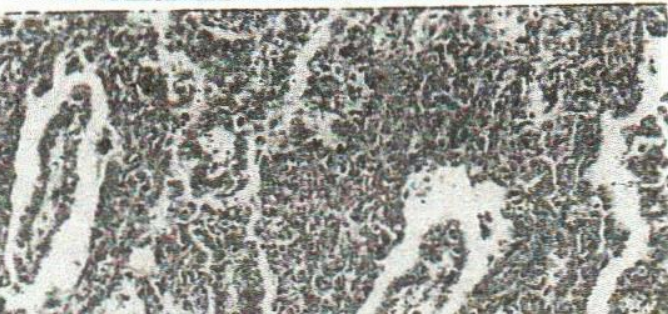

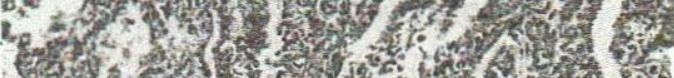

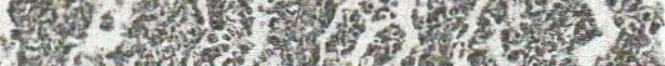

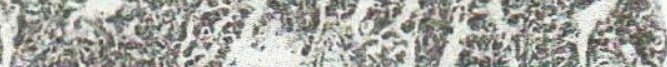

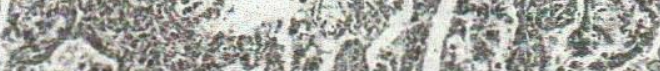

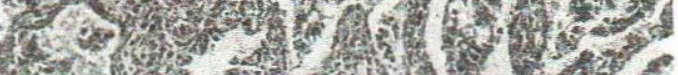

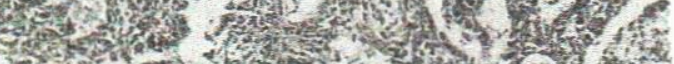

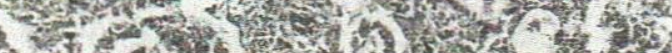
2 J

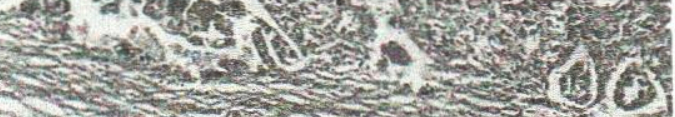
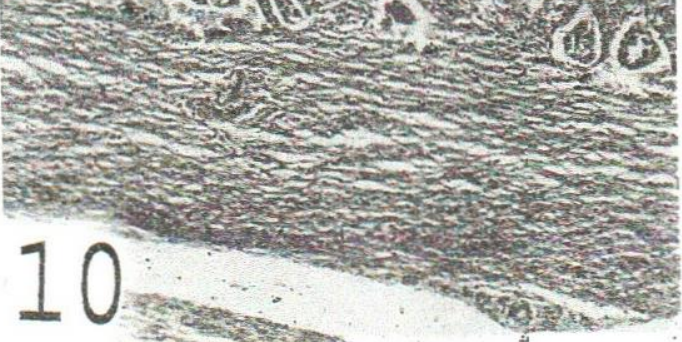


\section{LEGENDS FOR FIGURES}

Fig. 1: Endometrium of non pregnant ewe serologically positive for brucellosis showing necrobiotic changes of uterine glands and diffuse plasmolymphocytic infiltrations ( $H \& E$ X400).

Fig. 2: Uterus of non pregnant ewe serologically positive for brucellosis showing chronic endometritis characterized by diffuse plasmolymphocytic infiltrations with atrophy of uterine glands (H\&E X250)

Fig. 3: Uterus of non pregnant goat serologically positive for brucellosis showing presence of endometrial granuloma composed of a necrotic center surrounded by proliferated fibrous connective tissue and mononuclear cells ( $\mathrm{H} \& \mathrm{E}$ X250)

Fig. 4: Uterus of a pregnant goat serologically positive for brucellosis showing presence of a large endometrial granuloma composed of necrotic center and surrounded by aggregations of lymphocytes and macrophages. The glandular epithelium of endometrial glands are atrophied (H\&E X250).

Fig. 5: Placenta of a pregnant ewe serologically positive for brucellosis showing necrosis and desquamation of chronic epithelium, the lamina propria showing mononuclear cell infiltration and fibrous connective tissue proliferation (H\&EX250)

Fig. 6: Mammary gland of a goat serologically positive for brucellosis showing interstitial mastitis represented by focal and interacinar plasmolymphatic infiltrations with necrobiotic changes of acinar epithelium (H\&E X250)

Fig. 7: Supramammary lymph node of ewe serologically positive for brucellosis showing presence of pyogranuloma surrounded by fibrous connective tissue proliferations and mononuclear cell infiltrations composed mainly of lymphocytes and macrophages (H\&E X250)

Fig. 8: Lymph node of goat serologically positive for brucellosis showing sinus macrophagal infiltrations (H\&E X400)

Fig. 9: Liver of a goat serologically positive for brucellosis showing presence of a large pyogranuloma composed of dense aggregations of neutrophils surrounded by a layer of proliferated connective tissue. Also, lymphocytic infiltrations were present in-between hepatic cords (H\&E X250). 
Fig. 10: Testis of a ram serologically positive for brucellosis showing fibrous periorchitis, necrosis of seminiferous tubules with mononuclear cell infiltrations (H\&E X250)

\section{DISCUSSION}

Brucellosis is one of the most serious diseases of livestock, considering the damage done by the infection in animals. Decreased milk production, weight loss, loss of young, infertility, and lameness are some of the affects in animals. It is evident from the result of the present study that brucellosis is already prevalent among local livestock in breeding farms. The incidence of ovine brucellosis was reported in both district to be higher than that recorded by Doghiem et al. (1995). This may be attributed to, that most of samples of the present work were obtained from infected flocks, which have a history of abortion.

Age may influence the progression of infection. Sexually immature animals may show some resistant to infection whereas sexually mature animals are susceptible to infection, which in pregnant animals may result in abortion. The present study also revealed that rams are less susceptible to infection than ewes. This result had been reported by Alton, 1985. In this subject, Clell (1997) explained that, the major disease affecting sheep reproduction is ram epididymitis. In range flocks, the cause of $95 \%$ of the epididymitis is Brucella ovis. Some affected rams in almost all range flocks carry this bacterial agent. It spreads to new rams after they are added to the flock. The same author also added that, rams from farm flocks or purebred flocks usually do not have $B$. ovis epididymitis unless they have been rented out for use in a range flock, or in some other way have been mixed with infected rams or ewes. Virgin rams, kept separate from all older rams, will not have B. ovis

There is very little difference between goat species and breeds in their susceptibility to the infections, whereas breeds of sheep differ in their susceptibility. Milking breeds of sheep seem to be more susceptible to $B$. melitensis infection than sheep kept for meat production (Alton, 1985).

Bacteriological examination of aborted material is time consuming, laborious, costly, and cannot routinely be used as a diagnostic procedure in developed or developing countries. Thus, screening of serum samples as well as correlation of gross and microscopic lesions were considered to be the most diagnostic tools 
(Dennis 1980, Mayr, 1984). In the present study, the prevalent serological tests were used to verify the results of the examined samples. Farina (1985); Huber and Nicollotti (1986) stated that no reliance could be placed on the result of a single negative test of brucellosis. The seriological tests including RBPT with high sensitivity and Revanol test with high specificity are recommended. The former test is also recommended for screening flocks by Garin-Bastuji, et al. (1998).

Pathological changes accompanied brucella infections were usually present in the gravid uterus. The organism leaves the uterus to become localized in the udder, supramammary lymph nodes and other lymph nodes and spleen (Mayr, 1984 and El-Sergani et al., 1994). Granulomatous lesions detected in liver of seropsitive samples in the present study were expected by Jubb et al. (1985) and El-Sergani et al. (1994) to be caused by brucella as a facultative intracellular parasite. The udder showed focal and inter-alveolar inflammatory cell infiltrations, Doghiem et al. (1995) previously recorded these pathological findings. The same authors also reported that, the route of infection affect the picture of the disease. the animal may be in chronic stage serologically and when the organism invade other tissues it takes a long time and causes acute lesion in the organs according to the porta of entry. These results were in accordance with that reported by El-Gibaly et al. (1977).

The seropositive rams showed fibrous perorchitis and necrosis of seminiferous tubules which is similar to the result reported by Jubb et al. (1993) and Abdel-Hafez et al. (1995).

Finally, it could be concluded that, it is of great importance to detect the antibody level in the animal serum by applying serological tests as the shedding of brucella organism correlates with the amount of antibodies (Huber and Nicoletti, 1986). Diagnosis of brucella-infected animals is based on the evaluations of history as well as screening of serum samples and correlating gross and microscopic lesions.

\section{REFERENCES}

Abdel-Hafez, M.M.; Abdel-Kadder, H.A.; Bastawros, A.F.; El-Ballal, S.S. and Hamdy, M.E.R. (1995): Bacteriological and pathological studies on Brucella melitensis infection in dairy farm. 3rd Cong., Egyptian Society for Cattle Disease, Assiut Egypt. 266-274. 
Alton, G.G. (1985): The epidemiology of Brucella melitensis in sheep and goats, In Verger, J. M., Plommet, M., eds: Brucella meltensis, a CEC seminar. Martinus Nijoff, Dordrecht-BostonLancaster, 187-196.

Bancroft, D. and Stevens, A. (1982): Theory and Practice of Histological Techniques. $2^{\text {nd }}$ ed in.Churchill Livingstone (Edinburg, London, Melbourne).

Barsoum, S.A. (1980): Studies on brucellosis in cows in Egypt. M.V.Sc. Thesis, Fac. Vet. Med., Cairo Univ.

Clell, V.B. (1997): Reproductive disease of sheep. Utah State University Extension. Electronic Publishing\}.

Dennis, S.M. (1980): Infectious bovine abortion: a practioners approach to Diagnosis. Vet. Med. Small Animal Clinic, 3: 459-466.

Doghiem, R.E.; El-Gibaly, S.M..; Nafady, A.A.; Mousa, A.A.; Hamada, M.A. and Montaser, A.M. (1995): Morphopathological and immunopathological studies on sheep and goats infected with brucellosis. 3rd Sci. Cong., Egyptian Society for Cattle Diseases, Assiut Univ. 243-265.

El-Gibaly, S.M.; Goda, F.M.; Nada, S.M. and Sayour, E.M. (1977): Preliminary studies on epidemiology of brucellosis as a zoonotic disease in an infected area in Egypt. 1st Arab Biologists Cong. Alex., Egypt 26-30.

El-Sergani, M.; El-Gibaly, S.M.; Afify, M.; Barsoum, S.A. and Montaser, A. (1994): Pathological changes in bovine brucellosis. Egyptian J. Comp. Patol. Clin. Pathol. 7: 1-13.

FAO, WHO, OIE, (1993): Guidelines for a regional brucellosis control, Programme for the middle east . prepared by FAO cosultant at the workshop of Amman, Jordan 14-17 February, 1993.

Farina, R. (1985): Current serological methods in Br. melitensis diagnosis. Brucella melitensis. CEC seminar, Brussels, 139146.

Garin-Bastuji, B.; Blasco, J.M.; Grayon, M. and Verger, J.M. (1998): Brucella meltensis infection in sheep: present and future. Vet. Res. 29: 255-274.

Hamdy, M.E. (1989): Epidemiological studies on brucellosis in dairy animals to assess the probable source of infection to man. M.V.Sc. Thesis, Fac. Vet. Med., Cairo Univ.

Hamdy, M.E. (1992): Epidemiological studies on Brucella meltinsis in dairy animals and man. Ph.D.V.Sc. Thesis, Fac. Vet. Med. Cairo Univ. 
Huber, D.J. and Nicolotti, P. (1986): Comparison of results of card, Rivanol, complement fixation test and milk ring tests with the isolation of Brucella abortus from cattle. Am. J. Vet. Res., 47: 1229-1231.

Jubb, K.F.; Kennedy, P. and Palmer, N. (1985): Pathology of domestic animals Vol.1 pp 493, Acad. Press, N.Y.

Jubb, K.F.; Kennedy, P. and Palmer, N. (1993): Brucellosis In: Pathology of domestic animals 4th ed. Academic Press INC. London.

Mayr, A. (1984): Medizinische mikrobiologie, infections und seuchenlehre, pp720, Enke, Stuttgart.

Mikolon, A.B.; Gardner, I.A.; Anda, J.H.de and Hietala, S.K. (1998): Risk factors for brucellosis seropositivity of goat herds in the Mexicali Valley of Baja California, Mexico. Preventive Veterinary Medicine, 37: 185-195.

Refai, M. (1994): Brucellosis in animals in Egypt, An updated review. J. Egypt Vet. Med. Ass. 54:173-185.

Refai, M. (2002): Incidence and control of brucellosis in the Near East region. Vet. Microb. 90:81-110.

Selim, O.M. (1987): Sero-epidemiological studies on brucellosis in dairy cattle and man. M.V.Sc. Thesis, Fac. Vet. Med., Cairo Univ.

Shalaby, M.N. (1986): A survey on brucellosis as a cause of reproductive disorders in farm animals in Egypt. M.V. Sc. Thesis, Fac. Vet. Med., Cairo Univ. 